\title{
AS MICRO E PEQUENAS EMPRESAS E OS TRIBUTOS NO BRASIL
}

Mariana Amorim da Silva, Edilene Mayumi Murashita Takenaka, Marina Funichello.

Universidade do Oeste Paulista, Curso de Administração, Presidente Prudente, SP. E-mail: marimmorim@gmail.com

\section{RESUMO}

Um dos grandes entraves ao crescimento das empresas brasileiras é o excesso de tributos cobrados. O objetivo geral desse artigo foi apontar a questão das altas taxas tributárias incidentes nas Micro e Pequenas Empresas. Para tanto, a metodologia utilizada foi a abordagem descritiva qualitativa, com utilização de pesquisas bibliográficas e documentais. Possuidor de uma das maiores cargas tributárias mundiais, para proporcionar o equilíbrio nas cobranças, o governo criou o Simples Nacional, um regime que se baseia na receita bruta anual da organização, promovendo assim uma arrecadação tributária mais justa e equilibrada para essas empresas.

Palavras-chave: Micro e Pequenas Empresas. Tributação. Crescimento.

MICRO AND SMALL ENTERPRISES AND TAXES IN BRAZIL

\begin{abstract}
One of the major obstacles to the growth of Brazilian companies is the excess of taxes collected. The general objective of this article was to point out the high tax rates in Micro and Small Companies. For that, the methodology used was the descriptive qualitative approach, with the use of bibliographical and documentary researches. Owning one of the largest tax burdens in the world, the government has created Simples Nacional, a scheme based on the organization's annual gross revenue, to provide a fairer and more balanced tax collection for these companies.

Keywords: Micro and Small Business. Taxation. Growth.
\end{abstract}




\section{INTRODUÇÃO}

Nas últimas décadas, grandes empresas passaram a não necessitar de muitos colaboradores e espaço físico, oferecendo assim crescimento para as Micro e Pequenas Empresas que começaram a fornecer produtos e serviços para essas grandes empresas. (ABRANTES, 2012).

Segundo o Sebrae (2014, p.7), as Micro e Pequenas Empresas "vêm adquirindo, ao longo dos últimos 30 anos, uma importância crescente no país, pois é inquestionável o relevante papel socioeconômico desempenhado por estas empresas."

O crescimento das Micro e Pequenas Empresas ocasionam benefícios para a economia do país ao formalizar empregos e contribuir para o aumento do Produto Interno Bruto (PIB), além de impulsionar o empreendedorismo. Em 2018, os pequenos negócios foram responsáveis por 56,1 mil empregos formais no país. (SEBRAE, 2018).

Além de compreender a importância das Micro e Pequenas Empresas (MPEs), é necessário compreender tudo o que envolve em seus conceitos legais, quais são suas limitações, definições e tributos exigidos.

As MPEs diferenciam-se pelo faturamento anual (receita bruta) e pela quantidade de funcionários registrados e ainda oferecem um grande potencial para o crescimento econômico do país. Dessa forma, é de extrema importância mantê-las operantes, em crescimento e com uma baixa taxa de mortalidade.

Um dos critérios de impacto sobre as Micro e Pequenas Empresas são as elevadas taxas tributarias. No ano de 2007 o Sebrae realizou uma pesquisa voltada para as razões do encerramento das atividades das empresas, e "a carga tributária é o fator assinalado que mais impacta nas empresas" (SEBRAE, 2007, p. 38).

O objetivo geral desse artigo foi apontar a questão das altas taxas tributárias incidentes nas Micro e Pequenas Empresas.

\section{METODOLOGIA}

A pesquisa descritiva exige do investigador uma série de informações sobre o que deseja pesquisar. Esse tipo de estudo pretende descrever os fatos e fenômenos de determinada realidade. (TRIVINOS, 1987)

A abordagem utilizada será a qualitativa, que contribui para um melhor entendimento e que pode ser realizada de modo particular, com poucas pessoas, e tende a desenvolver a teoria. (TOULMIN, 1990)

O procedimento selecionado é a documentação indireta, realizada através da pesquisa bibliográfica, e documental, que se refere à utilização de materiais já existentes, tendo como exemplo artigos já publicados.

A pesquisa documental também será um instrumento de coleta de dados que proporciona a utilização de fontes diversas e informais. (FONSECA, 2002)

\section{RESULTADOS}

Os tributos estão presentes nos cotidianos de pessoas físicas, ou jurídicas, em produtos ou serviços adquiridos ou fornecidos.

De acordo com Da Cruz e Ross (2012), tributos é toda colaboração paga com dinheiro, respeitando o que está constituído na lei, para suprir gastos governamentais e para fornecer retorno para a sociedade através de prestações de serviços públicos.

Presentes em qualquer organização, os tributos são baseados em porcentagens conforme a rentabilidade da empresa e sua classificação. Sendo também subdividido em dois tipos: tributos não vinculados e tributos vinculados. (BRASIL, 1966)

Os tributos não vinculados, denominados como impostos, são aqueles já instituídos por lei, não estando ligado a nenhuma prestação específica do Estado ao sujeito. 
Os tributos vinculados estão representados como taxas e contribuição de melhorias, mas, diferentemente dos impostos, essas taxas ou contribuições de melhorias só poderão ser ordenados quando realizada atividade de interesse público ou a mesma colocada à disposição do contribuinte.

\section{MICRO E PEQUENAS EMPRESA - TRIBUTOS E CONTRIBUIÇÕES}

Toda organização possui tributos e contribuições de competência federal, estadual e municipal. Tributos que apresentam-se obrigatórios e modificados através de critérios, sendo o principal deles a receita bruta anual da organização.

Segundo Sebrae (2018), as Micro e Pequenas Empresas possuem diversos tributos e contribuições obrigatórios que conferem às três competências, sendo eles:

a) Tributos Federais - Contribuição Social sobre o Lucro Líquido (CSLL), Contribuição para Financiamento da Seguridade Social (COFINS), Contribuição para a Seguridade Social (INSS), Imposto sobre Produtos Industrializados (IPI), Imposto sobre a Renda de Pessoa Jurídica (IRPJ), Programa Integração Social (PIS).

b) Tributos Estaduais - Imposto sobre Operações Relativas á Circulação de Mercadorias e Sobre Prestações de Serviços de Transporte Interestadual, Intermunicipal e de Comunicação (ICMS).

c) Tributo Municipal - Imposto sobre Serviço de Qualquer Natureza (ISS).

Em relação aos tributos federais, apesar de possuírem um teto limite na receita bruta, tanto na classificação do Simples Nacional, como da Lei Geral das Micro e Pequenas Empresas, dentro desse limite ainda ocorrem muitas variáveis referentes ao valor que será arrecadado desses tributos e que tem como base o faturamento da receita bruta da organização.

Da Cruz e Ross (2012) afirma que um dos mais notáveis impostos dentro de uma organização é o ICMS, cada Estado apresenta uma normalização específica acerca desse imposto.

O ICMS que possui uma ampla faixa de incidência que abrange prestações de serviço de transporte e de comunicação e operações relativas à circulação de mercadorias, adquiriu esse perfil na Constituição de 5 de outubro de 1988 (BORGES; REIS, 2015, p.1).

A legislação concedeu aos Municípios e ao Distrito Federal o poder de instituir impostos sobre serviços, originando-se o Imposto Sobre Serviço de Qualquer Natureza (ISS) (FERREIRA, 2007).

O ISS estabelece uma limitação de percentual que deve ser aplicado na base de cálculo (alíquota), podendo variar de 2\% (mínimo) e 5\% (máximo); são aplicadas diferentes alíquotas variantes conforme cada tipo de serviço (MENDES, 2012 e BORGES; REIS, 2015b).

A partir do momento em que a lei municipal constitui o imposto ISS, não pode ocorrer uma generalização de serviços que serão contribuintes obrigatórios e nem todas as prestações de serviços estão sujeitas a cumprimento dessa norma, estando isentas dessa obrigatoriedade as prestações de serviços não acordadas na lista de serviços tributários, lista já pré-estabelecida pela Lei Complementar da União - LC no 116, de 2003 (MENDES, 2012).

\section{O SIMPLES NACIONAL}

O Simples Nacional apresenta-se como um regime de arrecadação em que a cobrança e fiscalização de impostos unifica oito impostos municipais, estaduais e federais em uma única guia de pagamento.

“O Simples Nacional é o regime tributário diferenciado, simplificado e favorecido, criado pela Lei Complementar no 123, de dezembro de 2006, em vigor desde julho de 2007, e que simplifica e reduz o peso dos impostos sobre os Pequenos Negócios no Brasil" (SEBRAE, 2017, p.4). 
O Simples Nacional busca a desburocratização no pagamento de impostos e o incentivo ao micro e pequeno empresário. Ao optar pelo Simples Nacional, as empresas realizam um único pagamento mensal, facilitando assim um maior controle financeiro da organização.

\section{MICRO E PEQUENAS EMPRESAS: FORMAS DE CLASSIFICAÇÃO E CARACTERIZAÇÃO.}

Receita anual e número de colaboradores são aspectos atribuídos a divisão acerca do porte das organizações.

As principais instituições que caracterizam o porte das organizações são a Lei Geral das Micro e Pequenas Empresa, o Banco Nacional do Desenvolvimento Econômico e Social (BNDES), a Agência Nacional de Vigilância Sanitária (ANVISA), o Instituto Brasileiro de Geografia e Estatística (IBGE) e o Ministério do Trabalho e Emprego (MTE).

Para enquadrar-se no Simples Nacional, o porte da empresa é classificado segundo o seu faturamento bruto anual, definindo que microempresa é a organização que possui um faturamento bruto anual menor ou igual a $\mathrm{R} \$ 240.000,00$ e que pequena empresa é a organização que contém um faturamento bruto anual maior que $R \$ 240.000,00$ e menor ou igual a $R \$$ 2.400.000,00. (SEBRAE, 2018).

Em 2018, o regime Simples Nacional sofreu algumas alterações em relação as MPEs sendo o principal, um novo limite para a receita bruta anual das pequenas empresas, em que o teto passa de $R \$ 3.600 .000,00$ para $R \$ 4.800 .000,00$. (SEBRAE, 2018).

Tal mudança traz a possibilidade de que um maior número de empresas passe a ser classificada como pequena empresa, fazendo jus a uma carga tributária mais equilibrada, representando uma expectativa de crescimento tanto estrutural da empresa como na contratação de novos funcionários.

\section{DISCUSSÃO}

Nos últimos anos, a economia brasileira cercou-se de incertezas com alterações governamentais e um alto percentual de desemprego. Sobreviver e crescer frente a tantas instabilidades passa a ser um grande desafio para qualquer empresa.

Apesar das dificuldades encontradas, as MPEs apresentam-se como organizações capazes de contribuir para o fomento de novos empregos e, consequentemente, de geração de renda.

Proporcionar um cenário motivador para geração e a permanecia das MPEs é algo benéfico para toda a sociedade. Entretanto, um fato agravante que contribui para o insucesso das mesmas são os inúmeros tributos, obrigatórios em toda empresa.

O sistema tributário brasileiro apresenta uma abrangência múltipla de tributos, muito dos quais com elevadas porcentagens, impactando de forma negativa no desenvolvimento das MPEs.

O Simples Nacional surge como um regime onde o principal intuito é assegurar que as MPE's possuiriam uma carga tributária diferenciada, equilibrada e justa.

\section{CONSIDERAÇÕES FINAIS}

É evidente que a esmagadora carga tributária incidente sobre as empresas brasileiras representa equívocos que podem culminar na total desmotivação de empresários e o consequente encerramento de empresas e a demissão de funcionários.

Quando o sistema governamental e as políticas públicas em seu todo proporcionam uma tributação justa e equilibrada, estimula os empresários ao investimento e crescimento da sua empresa e a economia passa a crescer como um todo, gerando emprego e renda. 


\section{REFERÊNCIAS}

ABRANTES, J. Teoria geral da administração: TGA: a antropologia empresarial e a problemática ambiental. Rio de Janeiro: Interciência, 2012.

BORGES, J. C; REIS, M. L. A. ICMS ao alcance de todos: parte geral. 5.ed. Rio de Janeiro, 2015 a.

BORGES, J. C; REIS, M. L. A. ISS ao alcance de todos. 2.ed. Rio de Janeiro, 2015 b.

BRASIL, CTN. Lei no 5.172, de 25 de Outubro de 1966. Dispõe sobre o Sistema Tributário Nacional e institui normas gerais de direito tributário aplicáveis a União, Estados e Municípios. Disponível em: < http://www.planalto.gov.br/ccivil_03/leis//5172.> Acesso em: 22 de fev. 2018.

DA CRUZ, V. R. L; ROOS, C. A. ICMS e o simples nacional: o reflexo do recolhimento de diferencial de alíquotas nas empresas optantes pelo simples nacional. Revista Eletrônica de Contabilidade, v. 6, n. 1, p. 67, 2012.

FERREIRA, F. C. et al. Norma padrão do imposto sobre serviços de qualquer natureza (ISS): materialidade e base de cálculo. 2007.

FONSECA, J. J. S. Metodologia da pesquisa científica. Fortaleza: UEC, 2002. Apostila.

MENDES, G. A. S. et al. Tributos Municipais: imposto sobre serviço de qualquer natureza (ISS).

SEBRAE. Análise do CAGED. Disponível em:

<http://www.sebrae.com.br/Sebrae/Portal\%20Sebrae/Anexos/Caged_fev\%202018.pdf > Acesso em: 20 de abr. 2018.

SEBRAE. Causa Mortais: 0 sucesso e o fracasso das empresas nos primeiros 5 anos de vida. Disponível em:

<https://m.sebrae.com.br/Sebrae/Portal\%20Sebrae/UFs/SP/Anexos/causa_mortis_2014.pdf,>201 4.

SEBRAE. Os Principais tributos que todo empreendedor precisa conhecer. Disponível em: <http://www.sebrae.com.br/sites/PortalSebrae/artigos/os-principais-tributos-que-todoempreendedor-precisa-conhecer,e40aa0b77d29e410VgnVCM1000003b74010aRCRD> Acesso em: 03 de mar. 2018.

SEBRAE. Participação das Micro e Pequenas Empresas na Economia Brasileira. Disponível em: Shttp://www.sebrae.com.br/Sebrae/Portal\%20Sebrae/Estudos\%20e\%20Pesquisas/Participacao\%2 Odas\%20micro\%20e\%20pequenas\%20empresas.pdf> Acesso em: 18 de abr. 2018.

SEBRAE. Relatório especial: Os impactos do Simples Nacional. Disponível em: < http://www.bibliotecas.sebrae.com.br/chronus/ARQUIVOS_CHRONUS/bds/bds.nsf/1513cca8cf40 729aa779c2d6d1885252/\$File/7733.pdf> Acesso em: 20 de abr. 2018.

SEBRAE. Simples 2018: o que você precisa saber sobre as mudanças na Lei Geral. Disponível em: <http://www.sebrae.com.br/sites/PortalSebrae/sebraeaz/o-que-voce-precisa-saber-sobre-asmudancas-na-lei-geral,bf3f040a2c620610VgnVCM1000004c00210aRCRD> Acesso em: 20 de abr. 2018. 
SEBRAE. Sobrevivência e mortalidade de empresas paulistas de 1 a 5 anos: relatório final. São Paulo: Sebrae, 2006.

TOULMIN, S. Cosmopolis: the hidden agenda of modernity. Chicago: University of Chicago Press, 1990.

TRIVIÑOS, A. N. S. Introdução à pesquisa em ciências sociais: a pesquisa qualitativa em educação. São Paulo: Atlas, 1987. 